\title{
A entrevista como método de pesquisa com pessoas em situação de rua: questóes de campo
}

\author{
Ana Paula Serrata Malfitano, Ana Cláudia Rodrigues Marques
}

\begin{abstract}
Resumo: A partir do campo de duas pesquisas de Doutorado, uma realizada na França e outra no Brasil, junto a pessoas em situação de rua, discute-se a utilização de entrevistas como método de pesquisa em campo. As autoras ocupavam, na ocasião, a posição de pesquisadoras e também de trabalhadoras de serviços de atendimento à população. A metodologia utilizada articula a observação participante, a participação observante e a realização de entrevistas aprofundadas. As reflexões aqui apresentadas centram-se na discussão da aplicação de entrevistas semidiretivas, com o objetivo de apreender a opinião daqueles sujeitos sobre os serviços dos quais são usuários. Com a análise sobre a recusa à entrevista, sua aceitação ou situações intermediárias, aponta-se que a entrevista pode ser um método efetivo para se aproximar do ponto de vista dessa população. Entretanto, os dados de campo mostraram que se apresenta mais efetiva para conhecimento acerca do universo da rua do que, efetivamente, sobre o conteúdo proveniente dos discursos dos entrevistados. Destacam-se a dupla posição das pesquisadoras, bem como as negociações implícitas e explícitas entre entrevistadores e entrevistados, ocorridas no decorrer do processo.
\end{abstract}

Palavras-chave: Técnicas de Pesquisa, Sem-Teto, Métodos.

\section{Interview with homeless peoples a method of research: issues of fieldwork}

\begin{abstract}
This study presents a field work report from two PhD researches, one in France and another in Brazil, with the homeless population, and discusses the use of interview as a method of research with the homeless. At the time, the authors were in the position of researchers and also of workers in care services to the population. Both researchers used the method of participating observation and interviews with different actors in the field. A reflection is made on the usage of open interviews with the homeless, trying to catch those people's points of view on the social services which they are users. Starting with examples of refusing, bargaining and accepting the interview proposal, it was concluded that interviews are an effective approach method to those people. However, the field data show that the interview appears to be more effective regarding the knowledge of the street environment, mainly, concerning the content ofthe interviewees' speech .It is discussed, on the interviews content, the context and who performs them, as well as the implicit and explicit negotiations on the process of fieldwork.
\end{abstract}

Keywords: Investigative Techniques, The Homeless, Methods.

\section{Introdução}

Partimos de duas pesquisas de campo de Doutorado, que usavam entrevistas semidiretivas com moradores de rua, com o intuito de apreender o ponto de vista destes em relação aos serviços que lhes eram oferecidos. A primeira pesquisa, realizada no Brasil (Campinas-SP), estuda a rede de serviços governamentais e não governamentais que trabalha com crianças e adolescentes em situação de rua, analisando seu funcionamento. A segunda pesquisa, realizada na França (Paris), pela segunda autora, estudou o papel de uma Equipe Móvel de Psiquiatria e Precariedade (EMPP) (A proposta da

Autor para correspondência: Ana Paula Serrata Malfitano, Departamento de Terapia Ocupacional, Laboratório METUIA, Universidade Federal de São Carlos - UFSCar, Rod. Washington Luís, Km 235, CEP 13565-905, São Carlos, SP, Brasil, e-mail: anamalfitano@ ufscar.br Recebido em 22/3/2011; 1 ${ }^{a}$ Revisão em: 11/5/2011; Aceito em 31/5/2011. 
Equipe Móvel de Psiquiatria e Precariedade (EMPP) concerne ao auxílio em saúde mental, notadamente, para pessoas em situação de rua. Caracteriza-se como uma equipe móvel que vai ao encontro das pessoas nas ruas, bem como realiza o trabalho conjunto às demais equipes que intervêm junto à população de rua. Proposta criada em 1997, em funcionamento em Paris, França), e sua intervenção junto a equipamentos de dispositivo de urgência social e a equipes de psiquiatria, bem como aos usuários destes serviços.

Além do papel de pesquisadoras, ambas as autoras estavam diretamente envolvidas com os objetos de estudo. A primeira atuava como terapeuta ocupacional de um serviço de saúde mental integrante da rede estudada (Centro de Atenção Psicossocial para Álcool e outras Drogas para o público infantojuvenil CAPSAdi), tendo contato direto com a população. A segunda era coordenadora da EMPP e, portanto, sem contato direto com a populaçáo.

$\mathrm{Na}$ França, o trabalho de campo específico nas ruas buscou o contato com nove pessoas, sendo que quatro foram entrevistadas, duas recusaram a entrevista e três não foram encontradas, apesar de muitas tentativas e buscas em pontos nos quais comumente circulavam. Foram escolhidas pessoas atendidas na rua pela EMPP, que viviam na rua havia muitos anos e que raramente frequentavam equipamentos sociais, incluindo os serviços de saúde. Devido à condição de trabalhadora na EMPP, havia previamente o conhecimento daquelas pessoas e o encontro com elas.

No Brasil, pelo trabalho de campo realizado especificamente nas ruas, entrevistamos cinco jovens, sendo que já os conhecíamos, havia mais de um ano, do serviço em que trabalhávamos. Foram entrevistados dois meninos de 15 e 17 anos, e três meninas, entre 15 e 19 anos. Pedimos permissão para entrevistá-los explicitando o contexto da pesquisa, todos aceitaram e alguns deles nos convidaram para acompanhá-los na rua durante um dia.

A metodologia de nossas pesquisas utilizou diferentes ferramentas: a observação participante, a participação observante ( De maneira diversa a Gold (2003), mas inspiradas pelos papéis dos pesquisadores que ele descreve, consideramos que o participante-observador busca objetivar sua realidade e sua condição, o que toma, na maioria das vezes, a forma de uma pesquisa acadêmica, com uma metodologia específica. Eventualmente, a pesquisa (e a observação) é para ele uma forma de participação, mas sua presença em campo é, antes de tudo, justificada por sua participaçáo enquanto membro do grupo - no nosso caso, especificamente, como profissionais em intervenção - e, apenas depois, na qualidade de pesquisador. O observador participante, em contraponto, é o pesquisador que vai ao campo para realizar uma investigação. Seu objetivo não é a participação, mas a observação. Idealmente, terminada a observação, a participação seria interrompida) e as entrevistas semidiretivas com diferentes atores do campo em estudo, a saber: gestores, profissionais e usuários, dentro e fora das instituiçôes ( Para a discussão da totalidade da metodologia empregada nas pesquisas, ver Malfitano (2008) e Marques (2010)). Neste artigo, abordaremos apenas as reflexóes metodológicas que dizem respeito às entrevistas realizadas nas ruas com os usuários.

É importante ressaltar dois aspectos que se articulam na experiência relatada: a nossa dupla posição - profissionais de intervenção e pesquisadoras - e as condiçóes de apreensão do ponto de vista da população em questão. $\mathrm{O}$ primeiro aspecto nos coloca entre as posiçôes da observaçáo participante e da participação observante. Uma vez que nossas pesquisas estavam centradas nas açóes, tanto as nossas quanto as dos outros atores sociais, podemos dizer que o fato de desempenhar um papel de intervenção há bastante tempo, modificou nossa maneira de observar. Há, assim, uma reciprocidade entre a participação e a observação, que, no nosso caso, foi dada por nossa dupla posição profissional.

O segundo aspecto abordado diz respeito à possibilidade de apreender o ponto de vista dos usuários (pessoas que vivem prioritariamente nas ruas) sobre os serviços que lhes são oferecidos. Assim, nos fizemos as seguintes perguntas: Quais são as ferramentas metodológicas adequadas para conhecer a opiniáo dessa população? Qual é a utilidade de entrevistar moradores de rua? Pode-se prescindir da entrevista? Como melhorar a utilidade da entrevista como método para apreender o ponto de vista dos usuários? Existe alguma diferença entre realizar uma entrevista nas ruas e fazê-la dentro de uma instituição?

Apesar de a entrevista com os usuários de maneira geral ser um método bastante usado, nos pareceu necessário, para atingirmos os objetivos de nossa pesquisa, encontrar estratégias para ir além do discurso inicial das pessoas na rua, classificado de estereotipado por Girola (1996). Esse tipo de discurso é frequentemente usado por essa população como uma estratégia para ter acesso a certos benefícios propostos pelos serviços sociais e sanitários (ADORNO; SILVA, 1999). Pretendíamos, portanto, ir além desse padrão, não com o intuito de atingir uma suposta verdade, o que não é uma questão para o pesquisador, mas para obtermos outras informaçóes que nos permitissem desenvolver uma reflexão 
mais aprofundada sobre os serviços em tela. Com esse embasamento, optamos pela realizaçáo de entrevistas na rua, buscando um espaço fora das instituiçôes, acreditando, assim, facilitar a emergência de discursos que, muitas vezes, não são possíveis dentro do ambiente institucional (Esse assunto foi discutido por Goffman (2001) e os estudos sobre a institucionalização, tendo como consequência a massificação, a despersonalização, a anulação dos desejos. Ver também como Vexliard (1998) mostra como as entrevistas dentro das instituiçóes produzem frequentemente um discurso convencional, preestabelecido, sem espontaneidade).

Pautamos também as condiçôes que favoreceriam ou não a realização e o conteúdo das entrevistas: ter anteriormente acesso a informaçóes sobre a pessoa, poder citar conhecidos em comum, ter algum vínculo prévio e a maneira de ir ao encontro da pessoa e de explicar a razáo do encontro, entre outras.

Essas questóes são importantes em toda investigação e já foram abordadas por diversos autores, não apresentando nenhuma originalidade. Acrescenta-se às reflexôes instituídas o fato de que, para a população moradora nas ruas, aquele local representa ao mesmo tempo um espaço público e privado (LOVELL, 1996) na discussáo sobre os espaços intersticiais, seu grau de publicidade ou privatização dos moradores de rua, a partir das práticas que constroem e aquelas que são construídas). Assim, a construçáo do contexto do encontro com essas pessoas se faz de maneira gradual, pois, não tendo limitaçôes do espaço privado na rua, o universo de possibilidades que rege esse encontro é demasiado amplo. Além disso, as pessoas em situação de rua são frequentemente abordadas por uma grande quantidade de interventores, profissionais ou voluntários, assim como por outros circulantes e moradores de rua. Aquele que chega pode vir incomodar, apoiar, agredir, ajudar, constranger, e um encontro pode representar todas essas possibilidades simultaneamente.

Visando contribuir com uma reflexão sobre o trabalho de campo junto a essa populaçáo, relatamos e discutimos a seguir algumas sequências de encontros realizadas.

\section{Cenas de encontros nas ruas}

\subsection{Senhora Tournier: recusa da entrevista}

A senhora Tournier foi atendida regularmente pela EMPP durante alguns meses e, nesse contexto, nós a encontramos três vezes. $\mathrm{Na}$ ocasião da tentativa da entrevista, fazia pouco mais de um ano que ela náo era mais acompanhada pela equipe.

Para nossa pesquisa, encontramos com ela quatro vezes. Na primeira vez, ela estava numa feira de rua e tivemos medo de incomodá-la, pois parecia pedir esmolas aos compradores. Quando se afastou da feira, pudemos abordá-la, digamos, "correndo atrás dela”. Foi necessário andar bem rápido para alcançá-la, por aproximadamente $30 \mathrm{~m}$, o que não é muito favorável para um encontro; teria sido preferível que ela tivesse nos visto chegar, detalhe importante em se tratando de um universo como a rua. Explicamos a razão de nossa visita e pedimos sua ajuda para nosso estudo, ao que a senhora Tournier nos respondeu: "Faz um ano e meio que eu faço perguntas por toda parte e ninguém me responde, por que tenho que responder as perguntas de vocês?”. Explicamos que a procuramos por já tê-la encontrado anteriormente, mas ela afirmou não se recordar e finalizou nosso encontro com um "Até logo, senhoras", dito com firmeza. A partir de uma recusa táo clara, questionamos se teríamos o direito de insistir, em outra ocasiáo. Optamos por uma nova abordagem, na tentativa de uma aceitação.

Em nosso segundo encontro, a Senhora Tournier nos acolheu de maneira sorridente e gentil, dizendo que estava cansada. Não comentamos sobre a entrevista, apenas a cumprimentamos e propusemos voltar mais tarde, diante de sua fala sobre o cansaço, o que ela aceitou prontamente. Perguntamo-nos se ela se lembrava do último encontro e retornamos posteriormente.

No terceiro dia, passamos duas vezes pelo local que habitava. Primeiramente, a Senhora Tournier nos recebeu, dizendo: "Bom dia, senhoras. Eu já lhes disse: 15 meses sem resposta para mim, logo não quero que venham me incomodar, eu não tenho mais respostas. Vấo ver outras pessoas por aí, tem muitas. Obrigada, até logo! Vocês mudaram de máscara, mas eu as reconheço. Não quero que me incomodem. Por favor, até logo". Diante de tal ênfase, retiramo-nos e retornamos em outra ocasiáo, na qual iniciamos explicando novamente nossas intençóes a ela, que disse: "Vocês me explicaram tudo isso no outro dia ali (indicando o lugar exato de nosso primeiro encontro) e eu já disse que ninguém responde às minhas questóes e, por isso, náo responderei nada a ninguém". Dessa vez, consideramos que essa recusa havia sido clara, precisa e objetiva, o que nos levou à conclusão da inadequaçáo da insistência.

A decisão sobre até que ponto insistir ou respeitar a recusa de contato é de extrema relevância na abordagem aos moradores de rua (FIRDION; 
MARPSAT; BOZON, 2000). Por um lado, faz-se necessária a presença por várias vezes, para que a constância permita o (re)conhecimento mútuo. É comum as pessoas na rua relatarem que "felizmente" os técnicos voltaram, apesar de sua recusa inicial, sendo, dessa maneira, a forma que muitos trabalhos iniciam. Todavia, como parece demonstrar a postura da Senhora Tourier, há momentos em que solicitam o respeito à sua opinião, não querendo ser incomodados. É, portanto, necessário não desistir na primeira recusa, mas sabendo compreender uma recusa definitiva.

Analisando nossa estratégia inicial para obter o consentimento da Senhora Tournier, consideramos que talvez tenhamos explicitado precipitadamente nossas intençôes, ao solicitarmos, de antemão, sua entrevista. Poderíamos ter estabelecido um contato inicial para, posteriormente, com alguma relação iniciada, apresentar nossa solicitação. Entretanto, não nos permitimos omitir a razão de nossa presença, pois não nos parecia a maneira eticamente adequada de abordagem nesse contexto. Dessa forma, nos colocamos na posição de quem apresenta demandas, sendo que ela estava em busca de respostas às suas próprias questôes. O que oferecíamos não interessava à Senhora Tournier naquele momento, pois apenas solicitávamos sua participação, sem nenhuma troca envolvida. Partimos, portanto, de uma negociação do contexto da entrevista que náo apresentava nenhuma vantagem para ela, o que pode ter impedido a realização da mesma.

\subsection{Senhor Maurice Lepage: entrevista em "banho maria"}

Havia quase dez anos, o Senhor Lepage era visitado pela EMPP. Se, durante muito tempo, a equipe teve dificuldade em realizar um atendimento efetivo, recentemente sua ligaçáo com eles havia ficado mais forte: recebia-os bem e aceitava frequentemente suas proposiçóes e encaminhamentos, como ir regularmente a uma estrutura social para tomar banho e consultar um médico. Nós já o havíamos encontrado, no trabalho em conjunto com a equipe, por três vezes, sendo que a última delas havia ocorrido alguns dias antes da proposta de entrevista. Ele prontamente se lembrou de nós e realizamos mais quatro encontros.

No primeiro, explicamos a razão pela qual o procuramos e propusemos a entrevista, proposta para a qual ele respondeu que pensaria sobre o assunto. Continuamos a conversa, sem nomeá-la de "entrevista", e avançamos na abordagem dos temas por nós escolhidos. O Senhor Lepage, entretanto, foi consistente na sua postura: na medida em que tentávamos avançar, ele se fechava, falando cada vez menos. Quando parou de nos olhar, compreendemos a mensagem e interrompemos a conversa, marcando o próximo encontro em uma data negociada. Ele aceitou nos encontrar, mas ainda náo havia acordado com a realização da entrevista.

Continuamos com essa postura, realizando os encontros e conversando sobre os pontos que havíamos elencado. Contudo, quando questionávamos formalmente se ele havia refletido sobre nosso pedido de entrevista, sempre respondia que ainda estava pensando sobre o assunto, o que mostrava que ele tinha conhecimento - mesmo que em parte - do porquê de nossas visitas, mas não formalizava sua anuência. Nesse contexto, avaliamos que seria invasivo solicitar a introdução de um gravador e permanecemos com as conversas "informais".

Ele nos recebia de maneira sorridente e, no terceiro encontro, disse que chegamos muito tarde, uma vez que fomos num horário diferente do habitual. Podemos interpretar essa fala como um acordo com a proposta do encontro, e, portanto, uma legitimação daquela conversa.

A cada encontro, ele falava de forma espontânea e fácil acerca de seu cotidiano, do que fazia, como se organizava quando chovia ou fazia frio, entre outros elementos. Entretanto, ele se fechava sempre que abordávamos suas relaçóes com os serviços ou quando tentávamos dirigir a conversa, não importando o assunto. Ele sempre era o condutor das temáticas, decidindo sobre o que falaríamos e também quando terminariam os encontros. Tínhamos, portanto, pouca margem de negociação sobre os desdobramentos daqueles momentos.

Formulamos a hipótese de que o senhor Lepage utilizava-se da não anuência à entrevista, bem como do controle dos conteúdos das conversas, para que permanecêssemos realizando os encontros com ele. Se, rapidamente, ofertasse o que pedíamos, não haveria motivo para voltarmos, o que, de fato, era concreto. Rullac (2006) discute a postura dos moradores de rua para a legítima condução a favor de seus interesses, em concordância com esse argumento.

O elemento de negociaçáo ficava explicitado nesses contatos. Para o Senhor Lepage, interessavam a visita, a conversa e outros ganhos ali colocados. Utilizava o que dispunha para alcançar suas solicitudes. Para nós, era necessária a realização da entrevista e fazíamos uso daqueles momentos para nos aproximarmos, quando permitido, dos pontos que buscávamos conhecer por meio de sua visão. 
Em uma dada situação, dissemos a ele que pararíamos de visitá-lo, em função das outras atividades de nosso estudo e, assim, não realizamos uma entrevista formal. Não obstante, o conteúdo acerca dos elementos de seu modo de vida foi detalhado, aproximando-nos do universo da rua e, principalmente, da negociação da relação.

\subsection{Antoine: aceitação "parcial" da entrevista}

Havíamos encontrado Antoine três vezes com a EMPP, sendo a última delas uma semana antes de lhe propormos a entrevista. Dentro do contexto de nossa pesquisa, realizamos dois encontros, mas, para efetivá-los, foi preciso ir sete vezes à praça onde vivia, pois ele raramente se encontrava no local, inclusive nos momentos em que havíamos agendado um horário para a visita. No primeiro encontro, ele nos recebeu sorridente, nos reconhecendo, agindo da mesma maneira que faz com os membros da EMPP. Supusemos termos sido beneficiadas por uma transferência de confiança, mas também questionamos se ele, um jovem morador de rua, teria recebido da mesma maneira duas moças desconhecidas que o procurassem. Em ambos os casos, havia um contexto favorável à realização da entrevista.

Explicamos a razão de nossa visita e ele concordou prontamente em conversar conosco, propondo irmos a uma cafeteria próxima, que ele conhecia. Pareceu-nos que ele entendia o contexto do nosso encontro como uma conversa entre amigos. A proposta de ir a um 'Café' reforçava essa impressão. Assim, sempre preocupadas em esclarecer o entrevistado, tentamos clarear nossas intenções e propusemos realizar a entrevista no local em que estávamos, o que diminuiu seu entusiasmo inicial. Isso ficou ainda mais evidente quando solicitamos a gravação da entrevista e ele disse se lembrar que teria um compromisso, devendo sair em cinco minutos. $\mathrm{Na}$ medida em que recontextualizamos nossas intençôes, seu interesse diminuiu e ele retrocedeu na aceitação.

Propusemos voltar mais tarde, após seu compromisso, e ele prontamente concordou. Quando retornamos, não estava mais lá e encontramos seu irmão, que também o aguardava, e nos disse: "Ele faz isso com todo mundo, nunca está presente no que combina". Voltamos dois dias depois e Antoine espontaneamente nos recebeu pedindo desculpas pelo não comparecimento ao encontro marcado, mostrando que se lembrava de nós, de nosso encontro e do que havia nos trazido. Isto ficou ainda mais evidente quando, na nossa presença, outras pessoas solicitaram uma conversa com ele e, entáo, negou, respondendo que tinha um "trabalho a fazer com estas duas moças".

Assim, fomos à cafeteria ao lado do local de morada de Antoine. Em meio a café, croissant e água, escolhidos por ele, foi possível realizar nossa entrevista, com sua participação ativa e detalhada. Observamos que ele fez durar, ao máximo, o café, talvez para prolongar aquela situação. Em alguns momentos, ele nos dizia que náo queria adentrar em determinados assuntos, e, de maneira gentil, mas firme, recusou a gravação da entrevista. Aceitamos prontamente e pudemos abordar todos os elementos desejados, tendo clara a escolha que ele fazia de aprofundamento ou náo das temáticas.

Essa experiência nos trouxe a reflexão acerca da negociaçáo do contexto do encontro, por várias razóes: ele concordou com o que poderia parecer com um encontro informal entre um homem e duas mulheres, que tomavam seu café da manhã juntos, porém discordou do que poderia contextualizar uma entrevista entre duas pesquisadoras e um morador de rua, recusando-se, por exemplo, em realizar a entrevista em seu ponto de moradia ou, ainda, em gravá-la. Ao final, ele insistiu em pagar o que havia consumido e, saindo do café, comentou que todos os homens têm o direito de paquerar, exceto pessoas como ele, por ser um morador de rua.

Despedimo-nos, marcando um encontro alguns dias depois. Tentamos encontrá-lo três vezes, sem sucesso. Semanas mais tarde, a polícia retirou seus pertences da rua, onde havia se instalado, e náo foi mais possível localizá-lo.

\subsection{José e Pedro: entrevista de passagem}

No trabalho de campo realizado no Brasil, partíamos de um vínculo já formado com os jovens para os quais solicitamos as entrevistas. Nesse contexto, dois jovens propuseram que passássemos um dia com eles nas ruas, para que pudessem explicar seu modo de vida. Apresentamos abaixo alguns trechos dessa caminhada.

José, com 16 anos, vivia na rua há quatro anos e, na época da entrevista, havia acabado de sair de uma comunidade terapêutica para tratamento do uso abusivo de substâncias psicoativas. Pedro, com 15 anos, vivia há três anos em alternância entre a rua e a casa de sua família, em uma favela em Campinas-SP. Nós os conhecíamos desde suas primeiras experiências nas ruas. $\mathrm{Na}$ época em que as entrevistas foram realizadas, os dois garotos dormiam em um abrigo provisório noturno e passavam o 
dia juntos, em circulação pelas ruas ou em outras instituiçôes destinadas a jovens em situação de rua.

Em nossa andança pelas ruas da cidade, eles nos apresentaram a alguns de seus amigos, mostraram o que faziam, como escolhiam os caminhos, como evitavam a polícia, suas atividades cotidianas e de lazer.

Eles escolheram as atividades possíveis de nos apresentar, aquelas que eram compatíveis com a nossa presença. Tal fato ficou evidente quando nos falaram de sua alimentação, mostrando os restaurantes nos quais era fácil ganhar comida, mas sem fazê-lo conosco, deixando implícito que essa ação não era pertinente realizar na nossa presença, ou seja, não era um código de que poderíamos compartilhar. Tendo compreendido a questão, sugerimos que comêssemos juntos um "cachorro quente", na medida em que nossa presença impedia que acessassem a refeição em seu modo habitual, e eles aceitaram.

Quando o momento contava com a presença de outras pessoas nas ruas, eles solicitavam a permissão para nossa presença. Chegamos a um local em que outros garotos pediam esmolas a carros parados no semáforo ou se ofereciam para limpar seus para-brisas. Nesse momento, por exemplo, fomos introduzidas com a apresentação deles: "Elas estão com a gente, trabalham em tal instituição, está tudo bem”. Daí, pudemos nos aproximar e conversar.

Nessa experiência, ressaltamos três aspectos relevantes na realizaçáo daquelas entrevistas. Primeiro, a caminhada na rua com os meninos foi uma possibilidade de entrar no seu universo e conhecer um pouco de sua dinâmica. José e Pedro foram os mediadores, que nos deram permissão para nos aproximarmos, observarmos e interagirmos com os jovens moradores de rua.

Eles nos levaram, inclusive, para equipamentos sociais que desconhecíamos na rede de serviços. Levaram-nos a um local público, na região central, que ofertava acesso gratuito à rede mundial de computadores à população em geral. José e Pedro frequentavam aquele espaço com regularidade para acessar jogos eletrônicos. Por meio da apresentaçáo e da explicação deles acerca das regras do local, igualmente às outras pessoas ali presentes, usamos o computador durante uma hora, tempo diário máximo concedido. Conhecendo um equipamento social do qual não tínhamos informação sobre seu funcionamento, na qualidade de trabalhadora daquela rede de serviços sociais, pudemos confirmar que eles têm acesso a uma rede própria para sua vida cotidiana, maior que aquela oferecida pelos serviços e que compreende recursos que, muitas vezes, desconhecemos.

O segundo aspecto a ressaltar nessa experiência foi a inversão de papéis, que se repetiu em diversos momentos nesse dia com José e Pedro, explicitamente na ocasião em que nos apresentaram o local e às pessoas, e realizaram a interlocução para nosso acesso, invertendo o papel que ocupávamos, quando em nossa posição de terapeutas ocupacionais do serviço de saúde. Também em Paris tal fato foi observado, na medida em que solicitávamos ajuda às pessoas nas ruas para nosso estudo. Uma discussão acerca de tal inversão é proposta por Girard (2006).

Por fim, o terceiro aspecto a ser ressaltado, é o fato de existirem elementos que só podem ser ditos nas ruas ou, ainda, que podem apenas ser mostrados. Conforme discutido por Girola (1996), quando caminhamos com as pessoas, há muitos elementos que aparecem a partir da observaçáo e dentro de seus discursos.

Durante a caminhada com os garotos, conversávamos sobre suas opiniōes a respeito dos serviços que utilizam. Esperávamos escutar críticas sobre os mesmos ou sobre suas equipes ou, ainda, que eles apontassem o que lhes interessavam em tais instituições, mas não foi o que ocorreu. Essas questôes foram abordadas por eles de forma superficial. Como já discutido em pesquisas anteriores (GREGORI, 2000; LOVELL, 1992), repetiram que vão a determinadas instituiçóes de acordo com suas necessidades no momento, de maneira aleatória, seguindo as eventualidades ao longo do seu dia.

\section{Entrevistas nas ruas:}

\section{negociação, aproximação e apreensão de modos de vida}

A experiência nos dois campos de pesquisa nos mostrou que a entrevista semidiretiva realizada nas ruas com as pessoas que nela moram é um método importante de abordagem, no qual destacamos dois aspectos: quanto ao seu conteúdo, por permitir a obtenção das informaçóes relativas ao tema da pesquisa; no nosso caso, o ponto de vista dos usuários acerca dos serviços que lhes eram ofertados. E, também, quanto ao contexto, na medida em que permite a emergência de outro discurso, diferente daquele obtido em entrevistas realizadas nos próprios serviços, alcançando outra apreensão, pelo pesquisador, do discurso e do universo das ruas, experienciada a partir de sua vivência pessoal em campo. 
Evidentemente, tal afirmação pode ser generalizada para a realizaçáo de entrevistas: o lugar no qual acontece tem certamente impacto sobre seu conteúdo. Assim, a entrevista realizada em abrigos, em instituiçóes de tratamento ou na rua apresentará informaçóes diferentes. Em nossa experiência, entretanto, a entrevista nas ruas trouxe, em termos de conhecimento do contexto, resultados tanto ou mais importantes quanto em termos de conteúdo. Mais ainda, é ao compartilhar esse contexto, essa inscrição territorial, o tempo da entrevista, que o pesquisador é capaz de acessar certos conteúdos. Portanto, trata-se, a priori, de uma observaçáo participante.

Nosso lugar em campo, como pesquisadoras e membros da equipe, trouxe algumas particularidades para a experiência. Apoiamo-nos no fato de já conhecermos as pessoas que entrevistamos, com informaçóes sobre suas vidas e sua relação com os serviços que frequentavam, numa "transferência de confiança", advinda da relação com toda a equipe envolvida nos serviços que compúnhamos. Assumimos, portanto, uma posição diferente de um contato "aberto" (RULLAC, 2006) ou "direto" (GIROLA, 1996) com as pessoas nas ruas, ou seja, sem a mediação de instituiçôes, pois tal mediação era nosso ponto inicial e de apoio para a entrada em campo. Pudemos, assim, abordar e aprofundar certos pontos que não eram originários daquele momento, mas sim da história anteriormente traçada junto àquelas pessoas. Tal fato trazia uma implicação ética relevante: buscar esclarecer nosso duplo papel, de pesquisadoras e técnicas, explicitando nossos interesses naquele momento às pessoas que entrevistávamos.

Do ponto de vista da duração do campo, esse conhecimento prévio das pessoas entrevistadas e a "transferência de confiança" utilizada permitiram uma redução significativa do tempo necessário para se buscar um discurso para além daquele disponibilizado de forma estereotipada aos muitos interventores com essa população. Quanto à negociação do encontro, essa pesquisa abordou diversas questôes: Como negociar a realização da entrevista? Pode-se caracterizar como um encontro entre amigos? Entre pessoas de diferentes classes sociais? Entre alguém que precisa de informaçôes e alguém que é especialista no assunto? Quem é o especialista sobre o quê? Como agenciamos as condiçóes? No momento em que as pessoas eram informadas de nossos objetivos e concordavam em nos encontrar, é possível considerar que elas também concordaram com a entrevista? Essas questốes estiveram sempre presentes nos encontros que realizamos, especialmente nos casos de Antoine e Maurice, que não explicitavam a concordância com a entrevista, mas prolongavam o encontro, solicitavam um novo momento, de acordo com os seus interesses. Antoine, com a intenção de ir a um 'Café', mostrava claramente que ele concordava em nos encontrar no contexto de uma relação “amigável" - palavra que ele usou várias vezes -, dizendo, ao mesmo tempo, que havia compreendido que estávamos lá para uma pesquisa. Para nós, o preço dessa negociação foi a não gravação da entrevista, visto que o contrário seria impor nossas condiçôes. É difícil dizer qual foi o preço para ele. Podemos supor que a negociação do encontro buscou conciliar o interesse de ambas as partes, com divergência entre as expectativas.

Por meio dos encontros relatados, compreendemos que a discussão metodológica das pesquisas direciona-se para além da aplicação de métodos e instrumentais que visem o rigor científico; a metodologia empregada, como ocorreu no nosso caso, pode propiciar a aproximação com a população em estudo e contribuir com a visão acerca de sua realidade, demandas e problemáticas que estão em análise. Portanto, para além do conteúdo em si, necessário para a realização da pesquisa, a aplicação das entrevistas nos contextos reais de vida daqueles sujeitos trouxe elementos efetivos acerca de suas vivências e, consequentemente, a construção de suas percepçóes sobre os elementos que a cercam, como os serviços que os atendem.

Podemos, então, afirmar que as experiências realizadas mostraram as possibilidades e os limites da realização de entrevistas nas ruas, explicitando a particularidade de nossa posiçẫo, juntamente com as indagaçóes acerca da aplicação de entrevistas, de suas diferenças de compreensão e interesses envolvidos, numa negociação sempre presente para um "encontro", para acesso a conteúdos buscados pelas pesquisas.

\section{Referências}

ADORNO, R. C. F.; SILVA, S. L. Cenas do mapeamento da rua: diários e discussôes dos educadores. In: LESCHER, A. D.; SARTI, C.; BEDOIAN, G.; ADORNO, R. C. F.; SILVA, S. L. Cartografia de uma rede. São Paulo: Projeto Quixote, UNIFESP, FSP/ USP, UNCDP, Ministério da Saúde, 1999. p. 9-32.

FIRDION, J. M.; MARPSAT, M.; BOZON, M. Est-il légitime de mener des enquêtes statistiques auprès de sans-domicile? Une question éthique et scientifique. In: MARPSAT, M.; FIRDION, J.-M. (eds.). La rue et le foyer. Paris: Press Universitaire de France, 
Institut National d'Études Demographiques, 2000. p. 127-149.

GIRARD, V. et al. La relation thérapeutique sans le savoir. Approche anthropologique de la rencontre entre travailleurs pairs et personnes sans chez-soi ayant une co-occurrence psychiatrique. L'évolution psychiatrique, v. 71, p. 75-85, 2006. http://dx.doi. org/10.1016/j.evopsy.2005.12.008

GIROLA, C. M. Rencontrer des personnes sans abris: Une anthropologie réflexive. Politix, v. 34, p. 87-98, 1996. http://dx.doi.org/10.3406/polix.1996.1033

GOFFMAN, E. Manicômios, Prisóes e Conventos. Tradução de Dante Moreira Leite. 7. ed. São Paulo: Editora Perspectiva, 2001.

GOLD, R. I. Jeux de rôles sur le terrain. Observation et participation dans l'enquête sociologique. In: CEFAÏ, D. Enquête de terrain. Paris: La Découverte. 2003. p. 340-349.

GREGORI, M. F. Viração: experiência de meninos nas ruas. São Paulo: Companhia das Letras, 2000.
LOVELL, A. Seizing the moment: power, contingency, and temporality in street life. In: RUTZ, H. J. (Org.). The politcs of time. Washington: American Anthropological Association, 1992. p. 86-107.

LOVELL, A. Mobilité des cadres et psychiatrie "hors murs". Raisons Pratiques. La folie dans la place: Pathologies de l'interaction, v. 7, p. 55-81, 1996.

MARQUES, A. Construire sa légitimité au quotidien: le travail micropolitique autour d'une Equipe Mobile de Psychiatrie-Précarité. 2010. 471 p. Thèse (Doctorat)-Ecole des Hautes Etudes en Sciences Sociales, Paris, France.

MALFITANO, A. P. S. A tessitura da rede: entre pontos e espaços. Políticas e programas sociais de atenção à juventude - a situaçáo de rua em Campinas, SP. 2008. 350 p. Tese (Doutorado em Saúde Pública)Universidade de São Paulo, São Paulo, 2008.

RULLAC, S. Critique de l'urgence sociale: Et si les SDF n'étaient pas des exclus ? Paris: Vuibert. 2006.

VEXLIARD, A. Le clochard. Paris: Desclée de Brouwer. 1998.

\section{Autores}

\section{Ana Paula Serrata Malfitano}

Doutora em Saúde Pública pela Universidade de São Paulo - USP, Estágio de Doutorado na École des Hautes Études en Sciences Sociales - EHESS, Centre de Recherche Médecine, Science, Santé et Société - CERMES, Paris, França, Financiamento da Coordenação de Aperfeiçoamento de Pessoal de Nível Superior - CAPES, Brasil, Professora Adjunta do Departamento de Terapia Ocupacional e do Programa de Pós-Graduação em Terapia Ocupacional da Universidade Federal de São Carlos - UFSCar, São Carlos, SP, Brasil

\section{Ana Cláudia Rodrigues Marques}

Doutora em Sociologia pela École des Hautes Études en Sciences Sociales - EHESS, Pesquisadora associada do Groupe Sociologie Politique et Morale (Grupo Sociologia, Política e Moral) - GSPM, Pesquisadora no l'Etablissement Public de Santé de Ville Evrard, Professora da Association pour le Développement, l'Enseignement et la Recherche en Ergothérapie - ADERE, Paris, França

\section{Contribuição dos Autores}

Ana Paula Malfitano e Ana Cláudia Marques trabalharam na concepção, pesquisa bibliográfica e redação final do texto. Ana Paula Malfitano foi responsável pelo campo de pesquisa no Brasil (Campinas, SP) e Ana Cláudia Marques pelo trabalho de campo na França (Paris). 